AGH DRILLING, OIL, GAS • Vol. 35 • No. $1 \cdot 2018$

http://dx.doi.org/10.7494/drill.2018.35.1.107

Vitalij Kułynycz*, Anna Pikłowska*, Oleh Kulynych**

\title{
OVERVIEW OF THE NANOPARTICLES APPLICATION FOR RESERVOIR ENGINEERING AND ENHANCED OIL RECOVERY (EOR) METHODS
}

\section{INTRODUCTION}

More than half of the energy consumed in the world (57.4\% in 2016, Fig. 1) comes from oil and gas. In addition, it is the limited resources, which is in deficiency (Fig. 2).

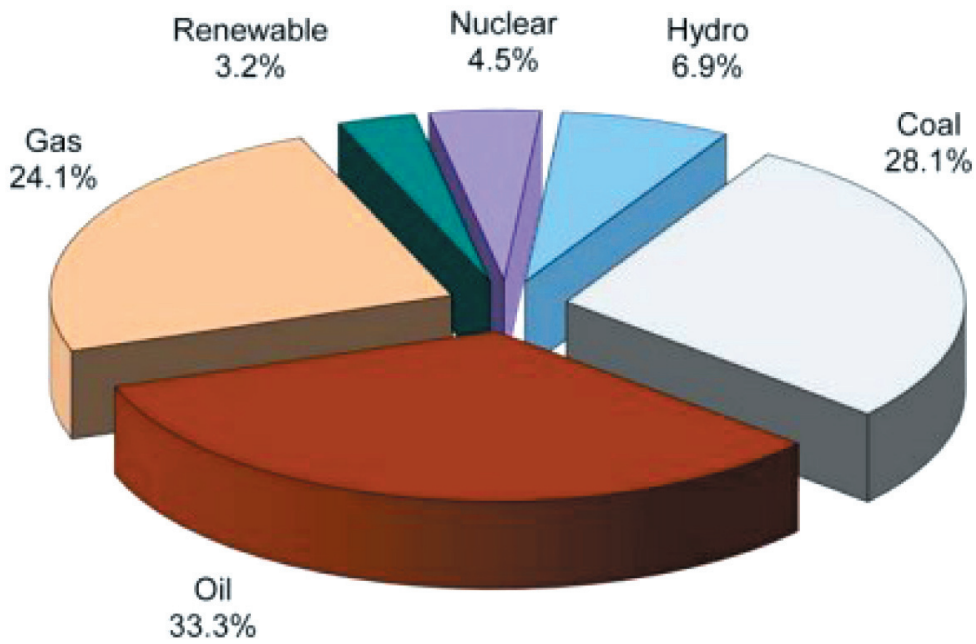

Fig. 1. Total primary energy consumption of the world in 2016 [1]

* AGH University of Science and Technology, Faculty of Drilling, Oil and Gas, Krakow, Poland

** National Technical University of Oil and Gas, Institute of Petroleum Engineering, Ivano-Frankivsk, Ukraine 


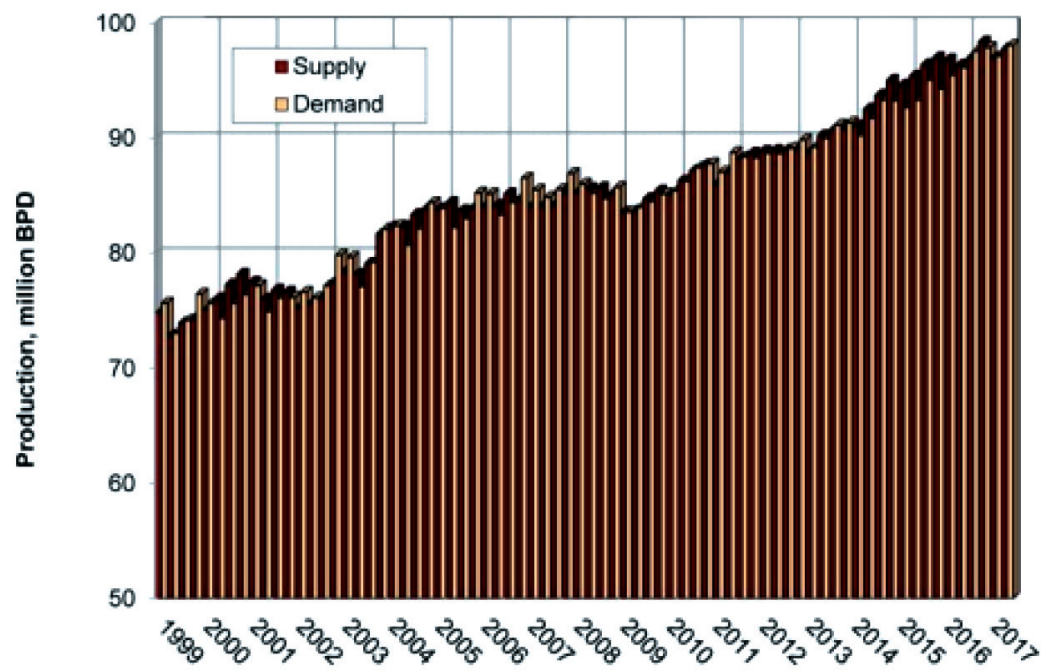

Fig. 2. Change of supply and demand of oil in the world [1]

Therefore, it is so important to increase production by increasing the recovery factor (RF) of reservoirs. Approximately half of the oil is still left in the reservoirs after primary and secondary oil recovery. To increase the oil recovery from the reservoirs it is necessary to apply Enhanced Oil Recovery (EOR) methods. The graphs (Fig. 1) illustrate the situation of the requirements and challenges of the oil and gas industry.

The EOR methods that are currently applied are often limited by a low cost efficiency, thus new and more efficient methods has to be developed. This is why the uses of nanoparticles are raised an interest in petroleum industry recently [2].

Nanotechnology takes advantage of synthesizing materials on a molecular scale (Fig. 3). With their very small size (less than $100 \mathrm{~nm}$ ), nano-sized particles have a very high surface specific area (compared to bulk) that gives them enhanced surface properties such as high reactivity [3].

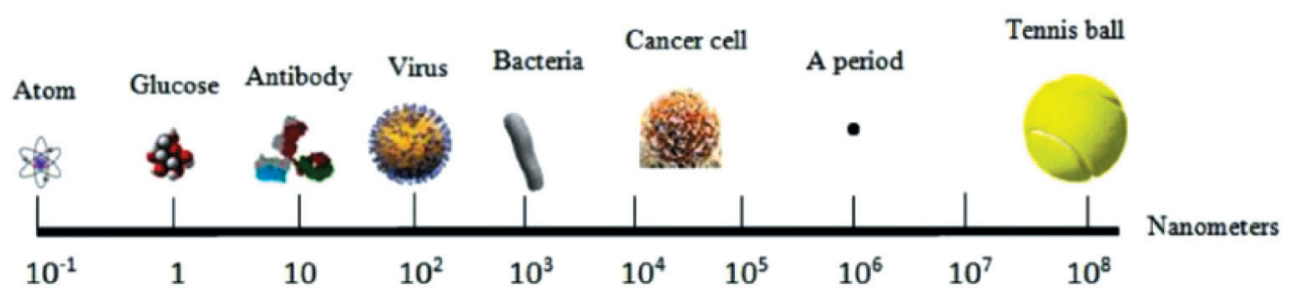

Fig. 3. Imaging of nanoscale [4]

Nanoparticles are becoming increasingly popular for different applications within the oil industry. In drilling, nanoparticles are used to decrease formation damage 
and increase drilling speed. They are also used as imaging contrast agents in exploration, to enhance resolution. The use of nanoparticles as an enhanced recovery agent in the laboratory has shown promising results as to changing several reservoir properties $[2,5]$.

\section{CHARACTERISTISC OF NANOPARTICLES}

Nanoparticles (NPs) are defined as particles with size ranges from $1 \mathrm{~nm}$ to $100 \mathrm{~nm}$. The diameter of one strand of hair is 80000 times thicker than $1 \mathrm{~nm}$ and our nails grow by $1 \mathrm{~nm}$ per second. $1 \mathrm{~nm}$ is in other words not visible for the human eye. For something to be visible for the human eye it has to be at least $20000 \mathrm{~nm}$. Nanoparticles have a very high surface to mass ratio. For some nanoparticles it could be as high as $300 \mathrm{~m}^{2} / \mathrm{g}$, which makes the nanoparticles very chemically reactive since large surface areas are available to react $[2,6]$.

Nanoparticles have an extensive range of unique characteristics for varied functionalities such as surface plasmon resonance, superior catalytic activity, intrinsic reactivity, great adsorption affinity and dispersibility [7,8]. Typically, nanoparticles are characterized by thermal, mechanical, physical and chemical properties. These properties span through material's grain boundary, particle size, surface area per unit volume, size of the particles, purity, thermal conductivity. The high surface area increases the thermophysical properties and the small particle size enhances their potentials as absorber fluids due to high potential of large surface coverage in heat transfer processes. With respect to the mechanical properties, nanoparticle exhibits high ductility, high average hardness, and maximum strain in comparison to other composite materials. The physical and chemical properties span through shape, size, structure, quantum confinement, lattice parameter and symmetry, charge, solubility, and surface coating [9, 10]. Nanoparticle surface area to volume ratio is over a million times higher than the conventional scales and the particle surface area is also higher than the bulk particles - micro and macro materials of the same mother source, which enhances their increased potentials even with a significantly low concentration of the materials in the system. effects. More so, nanoparticles exhibit strong chemical stability, irrespective of high temperature and pressure conditions of the reservoir and great selective adsorption behaviour which is vital for EOR process optimization [11-14].

Nanoparticles are categorized as magnetic, metallic and metal oxide nanoparticles. Magnetic (e.g. iron, cobalt etc. and the oxides), which containing magnetic elements and exhibit high magnetic field strength and unique quantum size properties. Rock surfaces coated with superparamagnetic nanoparticles have high capabilities to flow through micron-size pores across long distances in reservoirs [14]. 
Metallic nanoparticles (e.g. gold, silver, copper, and platinum) has exceptional properties that facilitate extensive usage, which is mainly due to its large surface to volume ratio, high potentials for inhibition of particle aggregation via immobilisation or separation on the heterogeneous supports, and high potentials for enhanced selectivity, size, and shape selective catalysis $[14,15]$.

Metal oxide nanoparticles (e.g. oxides of aluminium, zinc, silicon, magnesium, zirconium, cerium, titanium) are attractive for various processes especially in oil and gas owing to its varied structures, compositions, physical and chemical properties. These materials display high thermal conductivity - the degree to which they conduct electricity. Metal oxide nanoparticles also exhibit great potentials in hydrocarbon recovery processes via IFT reduction, wettability alteration, oil viscosity reduction [16-20]. Among these categories, the metal oxides are the most commonly used nanoparticles in EOR, as the material offers special unique structures, compositions, and properties [14]. Especially most commonly experimented on for EOR purposes is the silica nanoparticle (Fig. 4). Silica has proven especially useful to alter the wettability in a reservoir and reduce the interfacial tension. While other nanoparticles like $\mathrm{Fe}_{2} \mathrm{O}_{3}$ is usually applied for increasing the viscosity of the injection water. $\mathrm{Al}_{2} \mathrm{O}_{3}$ is good for reducing the oil viscosity. Silica has proven to have a lot of benefits as it consists of around $99,8 \%$ silicon oxide $\left(\mathrm{SiO}_{2}\right)$, which is the main component in sandstone, and therefore is already present in most reservoirs [2, 6, 21, 22].
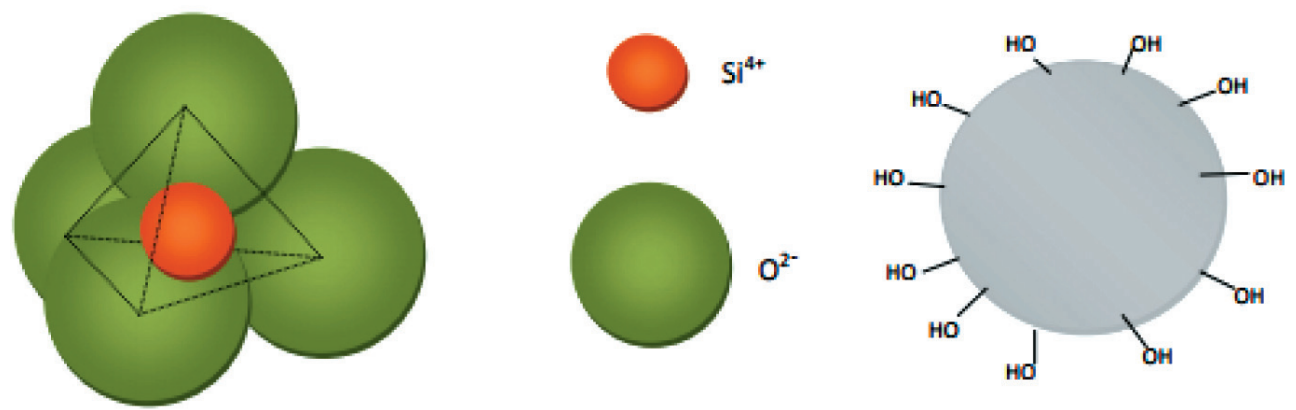

Fig. 4. Schematic diagram of the silica particle and silica nanosphere [23]

These nanoparticles are also cheap to produce and surface modifications are also easily done at a low cost. The silica nanoparticles can go from a hydrophobic to a hydrophilic state by adding hydroxyl groups or by the use of sulphonic acid. In addition the silica nanoparticles are very stable in suspension, this is due to the high surface conductivity of the particles $[2,19]$. 


\section{INFLUENCE OF NANOPARTICLES ON RESERVOIR PROPERTIES}

Nanoparticles has proven useful in altering several different reservoir properties in order to enhance the oil recovery. Nanoparticles can alter the rock surface wettability and permeability, also can reduce the interfacial tension and increase the displacing fluid viscosity.

\section{Wettability}

Nanoparticles can help alter the wettability in a reservoir to become more waterwet. This happens due to the nanoparticles forming a wedge-like film between the oil droplets and the rock (Fig. 5). Eventually there is a thin layer of nano fluid between the oil and the rock, making the reservoir more water-wet and thus the oil more mobile. The ability to form a wedge-like film between the oil droplets and the rock is due to the disjoining pressure gradient. This happens due to an overall increase in the entropy of the system, because the nanoparticles in the bulk liquid achieves a greater freedom. The excess pressure in this microstructure compared to the bulk liquid is the disjoining pressure, which is related to the ability of one fluid to spread out on a solid surface. The forces causing the disjoining pressure are electrostatic forces, structural forces and van der Waals' forces between the particles [2, 24, 25].

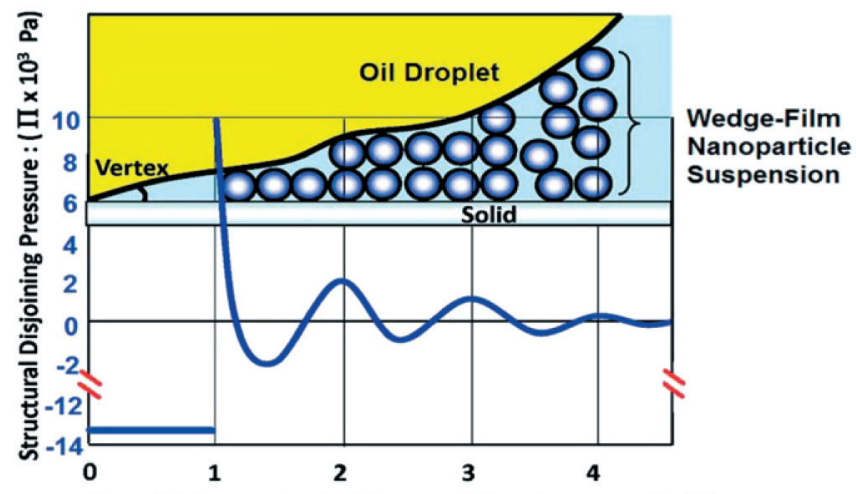

Film Thickness Scaled by Particle Diameter (h/d)

Fig. 5. Nanoparticles forming a wedge-like film between an oil droplet and the rock surface [5]

Many researchers reported results on the wettability alteration using NPs either alone or in combination with the surfactant. By changing formation wettability, capillary force will decrease and mobility of the oil phase will be enhanced [26]. The wettability alteration using NPs depends on several factors such as nature of NPs, hydrophobicity, 
nature of reservoir, and concentration of NPs. NPs can exhibit hydrophobic or hydrophilic characteristics depending on their surface ligands, stabilizers or surfactants used. Hydrophilic NPs should be preferred in the case of oil-wet formations while hydrophobic NPs should be used in water-wet formation. The optimum concentration of NPs is required in order to achieve the desired wettability [27].

\section{Permeability}

Rock permeability plays a key role during fluid flow in reservoirs as it impacts the fluid velocity and can impede or enhance fluid flow through a series of pore throats or channels. Since oil is typically recovered from formation rocks with micron-sized pores, nanoparticles are much smaller fine particles with unique size dependent physical and chemical properties that enhance easy penetration through the reservoir pores as the particle size is much smaller than the conventional rock pores [14].

Using nanofluid for EOR purposes can also alter the permeability of the reservoir. This happens by blockage of pore entrances, and can have both a negative and positive effect on oil recovery. The positive effect happens from selectively plugging pore channels in the reservoir, forcing the water to flow through oil-filled paths. This mechanism is especially helpful in a heterogeneous reservoir where oil is trapped in the narrower pore channels [22]. After water breakthrough, the brine injected into the reservoir tend to follow the same flow path. When a path where the water used to run is plugged, the water is forced to flow through other oil filled paths, where the water previously did not flow (Fig. 6). This leads to improved overall sweep efficiency in the reservoir. This will however have a negative effect on permeability as some of the nanoparticles are still left in the reservoir blocking pore channels. This is highly dependent on the amount retained and the severity of aggregation of nanoparticles [14].

a)

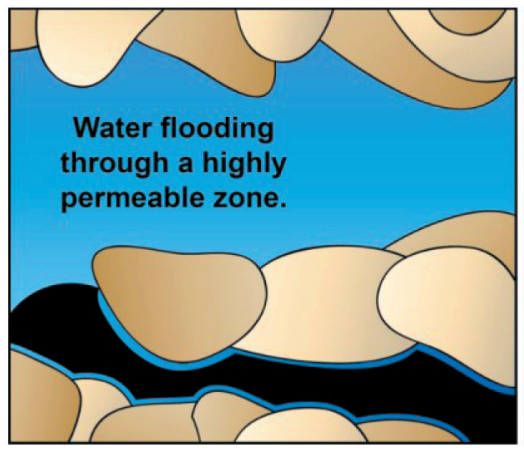

b)

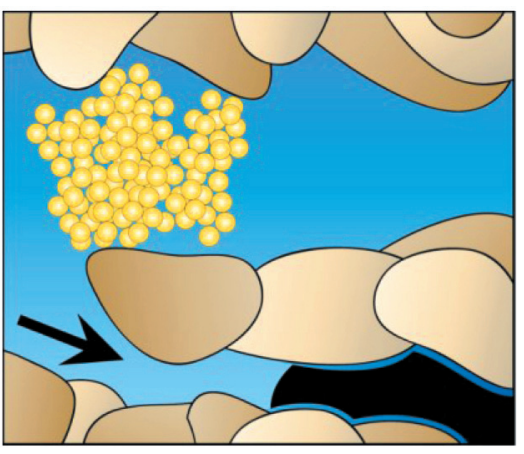

Fig. 6. Waterflooding through highly permeable zone before flooding with nanofluid (a); the flowpath of the water after injection of nanoparticles (b) [28] 
The blocking of pore throats thus can have a positive effect on oil recovery. But as the concentration of nanoparticles in nanofluid increases experiments have shown that the concentration reaches a critical value where the oil recovery starts decreasing. This is thought to be the point where the permeability impairment starts having a negative effect, where as it earlier had a positive effect due to leading the water through new flow paths. This might be caused by particles blocking the pore network instead of displacing more oil. Therefore the oil recovery is not proportional to nanofluid concentration, as the oil recovery tends to decrease as concentration reaches a critical point $[2,6,29]$.

\section{Viscosity}

Nanoparticles can also change the viscosity of the injection water, making the displacement efficiency of the injection fluid substantially higher. Other nanoparticles can also be used to decrease the oil viscosity, making the oil more mobile [30]. Nanoparticle based fluids otherwise called smart fluids for EOR are fluid systems containing nano-additives which exist in the form of suspensions or emulsions. These fluids are considered suitable for EOR processes owing to strong particle surface interaction with solvents, which helps to overcome density differences that make materials float or sink in a system. The nano-based smart fluids can display significantly high functional abilities in different systems while reducing the overall fluid cost, irrespective of the high cost of individual additives. Such suspensions or emulsions are known as nanofluids, nano-catalyst suspensions, or nanoemulsions [14]. The main objective of such use of nano fluids is to increase the sweep efficiency by decreasing the mobility factor $(M)$, which is the ratio between the displacing fluid and displaced fluid. A higher mobility ratio is desired for more oil displacement, under which has a higher sweep efficiency and less fingering effect in the reservoir. Nanofluids have been reported to be used to reduce oil viscosity and increase displacing fluid viscosity. Both factors will contribute to increase mobility ratio and as a result, boost oil recovery ratio [26].

$$
M=\frac{k_{w} \cdot \mu_{o}}{k_{o} \cdot \mu_{w}}
$$

where:

$$
\begin{aligned}
& k_{w}-\text { relative permeability to water }[-], \\
& k_{o}-\text { relative permeability to oil }[-], \\
& \mu_{w}-\text { water viscosity }[\mathrm{cP}] \\
& \mu_{o}-\text { oil viscosity }[\mathrm{cP}]
\end{aligned}
$$

The viscosity of nanoparticle dispersions depends strongly on the particle concentration, and that this correlation can be depicted by a unified rheological model. In addition, 
during flow in permeable media, the variation of shear associated with complex pore morphology and the interactions between the nanoparticles and tortuous flow channels can affect the viscosity of nanoparticle dispersion. The latter is particularly important if the concentration of nanoparticles in dispersion may change because of nanoparticle adsorption on mineral/fluid and oil/water interfaces or by mechanical trapping of nanoparticles [30].

\section{Interfacial tension}

To increase oil recovery ratio, one of the common strategies is to reduce the oil-water interfacial tension. The surface free energy that exists between two immiscible liquids is called interfacial tension. Oil recovery is directly related to a capillary number $\left(N_{c}\right)$, which is a dimensionless group that represents the ratio of viscous forces to the interfacial forces affecting the flow of fluid in porous media. Applied to water displacement of oil, the capillary number [27]:

$$
N_{c}=\frac{\mu_{w} \cdot u_{w}}{\phi \cdot \sigma_{o w}}
$$

where:

$$
\begin{aligned}
u_{w} & - \text { the velocity }[\mathrm{m} / \mathrm{s}], \\
\mu & - \text { the dynamic viscosity }[(\mathrm{kg} / \mathrm{m}) \cdot \mathrm{s}], \\
\sigma_{o w} & - \text { interfacial tension }[\mathrm{N} / \mathrm{m}], \\
\phi & - \text { porosity }[-] .
\end{aligned}
$$

To reduce the residual saturation, it is advisable that the capillary number increases. Because the capillary number depends on the IFT value, in order to increase it, the IFT should be reduced to a very low value. For this purpose surfactants, which lower the interfacial tension between two phases, have been added. NPs support in decreasing the IFT either alone or in addition with surfactants. Furthermore, the nanoparticles may also reduce adsorption of the surfactant on the surface of reservoir rock's surface [31].

Injection of nanoparticles, like hydrophilic silica, has proven to lower the interfacial tension. Li et al. [6] reported that this might be due to the hydrophilic part of the nanoparticles wanting to be in the aqueous phase, while the hydrophobic part wants to be in the oil phase. The nanoparticles then forms a layer on the interface between the oil and water, reducing the friction force and thus the interfacial tension between the two phases. This again leads to an increase in capillary number and therefore increased mobilization of oil [6]. 


\section{THE USING OF NANOPARTICLES TO ENHANCED OIL RECOVERY}

In this part of the article, authors reviewed several laboratory experiments investigating the use of nanoparticles for change reservoir parameters and increase in oil recovery ratio with nanoparticles.

When nanoparticles are injected into reservoir rocks, the system can yield various phenomenal behaviours: adsorption, desorption, transport, and blocking inclinations. The interactions between nanoparticles and the walls of the porous media can lead to adsorption if the force of attraction is higher than the repulsive with the reverse leading to desorption, however, adsorption and desorption are dynamic balance process that is controlled by the total force existing between the porous media wall and nanoparticle. Blocking can occur if the nanoparticle diameter appears bigger than the size of the pore throat or due to particle to particle aggregation at the pore throat which can inhibit efficient transport of nanoparticle based fluids through the porous media [14, 32].

Nanoparticles can easily pass through small pore throats in reservoirs formations, however, physicochemical interactions between nanoparticles and between nanoparticles and rocks can cause a significant retention of nanoparticles. Al-Anssari et al. [33] performed the research to demonstrate the penetration, adsorption, and retention of $\mathrm{SiO}_{2}$ nanoparticles in limestone porous media after nanofluid injection using energy distractive spectroscopy (EDS) measurement (Fig. 7). According to the authors, nanoparticles can be very efficient for wettability alteration and interfacial tension reduction in subsurface applications since they have the ability travel for significant distances within the porous media. Smaller particles were more efficient to penetrate in the porous media and the particle retention rate could increase with initial particle size. Salinity was the most significant factor which negatively impact the transport of nanoparticles due to the screening effect of salts on the repulsion forces between particles in the injected fluid leading to larger aggregates. The increase in temperature reduced the retention of nanoparticles owing to the changes in surfaces charges of silica nanoparticles and carbonate surface. Authors concluded that silica nanoparticle can be an effective agent in subsurface industries if accompanied with stabilizing agent to avoid the screening effect of salts [33].
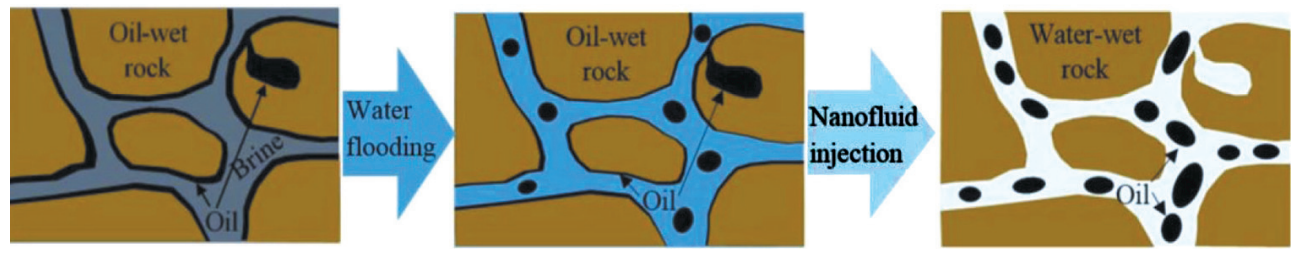

Fig. 7. Effect of nanofluid injection on wettability and oil-recovery of originally oil-wet reservoirs [33] 
Nazari et al. [34] conducted a preliminary wettability study for eight different NPs and investigated the performance of selected $\mathrm{NPs}\left(\mathrm{CaCO}_{3}\right.$ and $\left.\mathrm{SiO}_{2}\right)$ for EOR processes. Nanofluid injection induced increase of oil recovery by $8-9 \%$. Moreover, the active role of $\mathrm{CaCO}_{3}$ and $\mathrm{SiO}_{2}$ NPs was testified by the spontaneous absorption results [34].

Another group of authors, Karimi et al. [35], observed wettability alteration in carbonates surface with zirconium oxide nanofluid. With microscopic imaging and theoretical calculation, authors proposed the wettability alteration was due to $\mathrm{ZrO}_{2}$ deposition on the rock surface and governed by the partition coefficient of nanomaterial in water and oil phases. Their result also showed, that the wettability alteration by nanofluid is a slow process that may take days to finish $[26,35]$.

Sepehrinia and Mohammadi [36] conducted a research on aluminum oxide and zirconium oxide on oil-wet dolomite surface with different dispersing medium such as cationic, anionic or nonionic surfactant. Their result showed that cationic surfactant was more effective in altering wettability of oil-wet dolomite rock to more water-wet condition [36].

Tola et al. [37] have investigated wettability alteration of sandstone and crude oil surfaces contacting nanofluids formulated by $\mathrm{ZnO}$ nanoparticles. The $\mathrm{ZnO}$ nanofluid was mixed by dispersing into water solution of Sodium Dodecyl Sulfate that was an anionic surfactant. $\mathrm{ZnO}$ concentration in the fluid ranged from $500 \mathrm{ppm}$ to $5000 \mathrm{ppm}$. Oil film spread on glass plate and surface of Berea sandstone saturated by light crude oil were used to measure fluid wettability evaluated by the contact angle of fluid droplets with the sessile drop methods. It had been confirmed that the $\mathrm{ZnO}$ nanofluid had a potential to shift wettability to more water -wet condition on the surfaces of oil film and sandstone saturated with oil. The IFT of crude oil with $\mathrm{ZnO}$ nanofluid didn't change much at low concentration from $0 \mathrm{ppm}$ to $400 \mathrm{ppm}$. The $\mathrm{ZnO}$ nanofluid by dispersing $\mathrm{ZnO}$ nanoparticles from $500 \mathrm{ppm}$ to $1000 \mathrm{ppm}$ into and SDS solution of $2500 \mathrm{ppm}$ had a good potential of altering wettability of the sandstone surface to more water-wet than the other fluids [37].

In the petroleum industry core flooding tests are commonly used procedure to specify the oil recovery at specific reservoir conditions. The oil recovery is determined by the various factors of NPs injection, however the concentration of NPs is the most important agent in core flooding experiments. To achieve maximum recovery, the optimal concentration of NPs should be determined. Higher concentrations of NPs have no significant impact on the recovery factor, this is only the reason of increase the cost. The second important element - ionic contents in a reservoir is variable depending upon the nature of reservoir and formation. Usually for all types of chemical EOR core flooding experiments the influence of salinity on oil recovery is defined. The dispersion of NPs can be destabilized by salinity higher than the critical values. Selection of appropriate NPs for typical reservoir conditions is very important because type of NPs influences of oil 
recovery factor. And finally the effect of NPs on surfactant efficiency - the results from the core flooding tests proved that factors which played a significant role in improving oil recovery are quantities, the concentrations and the types of NPs. Performance of NPs during the core flooding experiments is very much conditioned by the addition of salts and this to a large extent affects the amount of oil that can be recovered. Also, factors that will affect additional oil recovery are the mechanisms of interaction and transport of NPs in reservoir rocks, similarly [27].

Ehtesabi et al. [29] used $\mathrm{TiO}_{2}$ NPs in core flooding test using sandstone core. Their experiences showed that using a brine of 5000 ppm leads to $49 \%$ of the oil recovery, while the use of $\mathrm{TiO}_{2}$ NPs $(0.01 \%)$ increased oil recovery factor up to $80 \%$ (31\% additional oil recovery). On the other hand, concentration of $\mathrm{TiO}_{2}$ NPs to $1 \%$ showed no significant effect on the recovery factor. Recovery ratio obtained in that way was lower than what was achieved using brine only. This team also conducted experiments with core flooding using $1 \mathrm{wt} \% \mathrm{TiO}_{2}$ amorphous NPs. The recovery factor was established at the level of $23 \%$, which was less than the recovery factor obtained when only brine was used. This indicated the validity of procedures for the selection of the optimal amount of nanoparticles [29].

Bayat and colleagues [38] conducted a number of experiments to investigate the displacement effects of three metal oxides $\mathrm{NPs}\left(\mathrm{Al}_{2} \mathrm{O}_{3}, \mathrm{TiO}_{2}\right.$, and $\left.\mathrm{SiO}_{2}\right)$ on the quantity and quality of the produced oil from an intermediate limestone sample at different temperatures [41]. The displacement analysis showed an average of $47.3 \%$ oil recovery at $26^{\circ} \mathrm{C}$ for water flooding by the use of brine $(\mathrm{NaCl} 0.3 \mathrm{wt} \%)$. At the same injection conditions $\mathrm{Al}_{2} \mathrm{O}_{3}, \mathrm{TiO}_{2}$, and $\mathrm{SiO}_{2}$ increased the oil recovery to $52.6 \%, 50.9 \%$, and $48.7 \%$, respectively. The oil recovery at ambient temperature $\left(26^{\circ} \mathrm{C}\right)$ using $\mathrm{Al}_{2} \mathrm{O}_{3}$ nanofluid was 1.5 and 2.25 times greater than that of $\mathrm{TiO}_{2}$ and $\mathrm{SiO}_{2}$, respectively. The highest oil recovery ratio was represented by the $\mathrm{Al}_{2} \mathrm{O}_{3}$ NPs and was assigned to its ability to lower the capillary force of oil during the displacement test on the recovery of heavy crude oil [38].

In addition to wettability alterations and IFT reduction, nanofluids can be used to increase the viscosity of the injection fluid or to lower the viscosity of the oil. Nanoparticles can also be used to selectively plug pore channels, leading the water through new flow paths. One of the main benefits of using nanoparticles for EOR purposes is that only a very small concentration of nanoparticles is required. Experimentally the incremental oil recovery has been found to be decreasing when the nanoparticle concentration reaches a critical value. For the use of silica nanoparticles in water-wet Berea sandstone this critical value had been found to be at around $0.05 \mathrm{wt} \%$. This is very desirable both considering the economy and the environment [2].

A mathematical model was proposed by Ju et al. [39] for the migration and adsorption of hydrophilic nanoparticles through porous media in the presence of oil. They 
evaluated the change in porosity, absolute permeability and relative permeability after coreflooding with hydrophilic nanoparticles. Oil recovery increased by $9.3 \%$ when 2 vol\% hydrophilic nanoparticles were added to water. The numerical results showed that nanoparticles were retained in the pores (adsorbed on the pore walls) and the absolute permeability and porosity decreased. Relative permeability to oil increased, whereas relative permeability to water decreased after injecting nanoparticles [39]. Gu et al. [40] investigated the flow of hydrophobic nanoparticles through porous media and proposed a slip velocity model for capillary flow and a slip boundary condition. The authors experimentally observed that hydrophobic nanoparticles could adsorb on porous walls, which changed the contact angle from preferentially water-wet to preferentially oil-wet. The coreflood experiments showed that effective permeability of water increased by $47 \%$ after hydrophobic nanoparticle suspensions were injected [40]. Sun et al. [41] reported that the motion of nanoparticles in the laminar flow was mainly Brownian, and that the deposition of nanoparticles was independent of flow velocity. In this sense, smaller particles deposited more easily on the wall surface than larger ones [30, 41].

A series of microfluidic experiments were carried out to test the efficiency of nanofluids for heavy oil recovery. The experiments also evaluated the fluid-fluid interactions through a 2D, transparent, and hydrophobic micro-reservoir. Four types of displacing fluids; distilled water, nanofluid (silica nanoparticles dispersed in water), complex fluid (silica nanoparticle with Tween 80 dispersed in water), and surfactant (Tween 80) solution, were used to displace an Alberta heavy oil sample diluted with heptane. The results demonstrated that adding nanoparticles and surfactants enhance the mineral oil recovery factor, measured through the swept area, by $18 \%$ and $39 \%$, benchmarked against the original 48\% recovery using distilled water injection [42].

Kazemzadeh et al. [43] analyzed the $\mathrm{SiO}_{2}, \mathrm{NiO}$ and $\mathrm{Fe}_{3} \mathrm{O}_{4}$ NPs effects on the recovery of heavy oil. In order to simulate oil production in the presence of NPs, a structure of glass micromodel equipment was used in core flooding procedure. The flooding based on $\mathrm{SiO}_{2}, \mathrm{NiO}$, and $\mathrm{Fe}_{3} \mathrm{O}_{4}$ improved the oil recovery by $22.6 \%, 14.6 \%$, and $8.1 \%$, respectively, when water injection was measured as the reference point. It was concluded the greater oil recovery presented by $\mathrm{SiO}_{2}$ was probably result of its effectiveness to reduce interfacial tension and wettability alteration in porous media [43].

A team of researchers headed by Alomair tested the recovery of heavy oil sandstones under the influence of four types of nanoparticles $\left(\mathrm{Al}_{2} \mathrm{O}_{3}, \mathrm{TiO}_{2}, \mathrm{SiO}_{2}\right.$ and $\left.\mathrm{NiO}\right)$ at different concentrations. Compared to the base recovery (water injection), core flooding tests by $\mathrm{SiO}_{2}$ and by $\mathrm{Al}_{2} \mathrm{O}_{3}$ showed higher recovery $-\mathrm{SiO}_{2}$ increased the recovery by $0.958 \%$, while $\mathrm{Al}_{2} \mathrm{O}_{3}$ increased the recovery by $4.895 \%$. Because both $\mathrm{SiO}_{2}$ and $\mathrm{Al}_{2} \mathrm{O}_{3}$ showed high oil recovery, they mixed both NPs and conducted a flooding test, and consequently a enermous oil recovery was observed - it was $23.724 \%$ higher than the water injection recovery [44]. 
As mentioned earlier especially most commonly experimented on for EOR purposes is the silica nanoparticle due to altering the wettability in a reservoir and reducing the interfacial tension.

Roustaei and coworkers [45] analyzed oil from two different Iranian light and intermediate reservoirs at an angle of enhancing recovery by the performance of modified $\mathrm{SiO}_{2}$ NPs. The results of their experiments showed that the total oil recovery increased after the application of modified $\mathrm{SiO}_{2}$ NPs in two core samples saturated with light and intermediate oils: the water flooding recovery of the first plug (saturated by light oil) was $54 \%$ and for second plug (saturated by intermediate oil) was $41 \%$. The oil recovery was increased by $25 \%$ and $14 \%$, respectively, in the first and second core sample. It was shown that a comparison between the recovery ratio analysis discovered that nanofluid could produce a significant amount of oil after primary and secondary recovery processes. Moreover, they reported that the capability of nanofluid in EOR have depended on the oil type and varies from different oil reservoirs [45].

Hendraningrat et al. [46] studied zero dimensional nanoparticles sweep efficiency with glass microchannels and microchips (Fig. 8). He found that $0.1 \mathrm{wt} \%$ silica particles flooding can achieve higher oil recovery ratio compared to the brine control group. Researchers have also tried other zero-dimensional nanoparticles than silica for enhanced oil recovery [46]. Ogolo et al. [47] tested nanoparticles other than silicon dioxide, such as aluminum oxide and magnesium oxide, with different solvents. In these study, aluminum oxide with distilled water achieved the most successful flooding result. This solution delivered $12.5 \%$ more on oil recovery ratio than water flooding [47].

a)

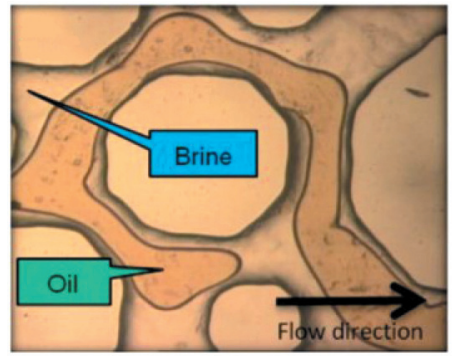

b)

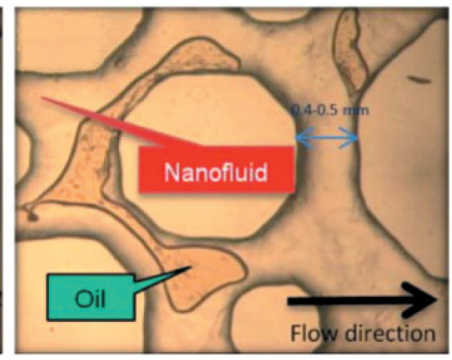

Fig. 8. Flooding experiment carried out with microfluidic chip (a) brine flooding (b) silica particle nanoflooding [46]

Li et al. [48] conducted many flooding experiments using the different silica NPs to study the effect of hydrophilic silica nano-structure particles and hydrophilic silica colloidal NPs on oil recovery. They obtained the same results that injecting both types of nanofluids and also pointed out that both types could increase oil recovery even though with very low concentration $[48,49]$. 


\section{CONCLUSIONS}

With the continuous rise in energy demand and decline in conventional reserves, the oil industry is constantly in search of inventive and novel approaches to optimize hydrocarbon recovery. The uses of nanoparticles are raised an interest in petroleum industry recently.

Beside the available and commonly used injection fluids used in the traditional EOR processes such as gas, water and chemicals, there is a quite large group of nanoparticles (for instance $\mathrm{SiO}_{2}, \mathrm{TiO}_{2}$ and $\mathrm{Al}_{2} \mathrm{O}_{3}$ ), which can be distinguished. In regard to utilization of NPs, these compounds are standing out because of particle sizes, which are very small, with the result that NPs have a very high surface to volume ratio. The large surface area increases participation of atoms on the NP surface. By this attribute, their usability in enhanced oil recovery is very high, because of NPs can easily flow through porous cores/rocks without intense permeability reduction and becoming trapped eg. in throat. This feature is a great advantage and incerases the EOR effectivity of the injection fluids.

Based on a literature review, the authors came to the conclusion that nanoparticles have shown great prospects for oil recovery applications. Nanoparticles can reduce the interfacial tension, increase the displacing fluid viscosity, generate foams and emulsions and alter the rock surface wettability through creating structural disjoining pressure and nanofilm formation. Depending on the surface properties of nanoparticles and oil polarity, nanoparticles can migrate to the oil-water interface, decrease the interfacial tension between water and residual oil, break up the trapped oil in forms of small droplets, and stabilize emulsions at reservoir conditions.

Another important advantage is the price of NPs, the cost of which is typically less than chemicals. Furthermore, most of the NPs used are environmentally friendly materials compared to another chemical substances applied to reservoir (for example, most of the silica NPs are silicon dioxide, which is the main component of sandstone). In conclusion, NPs are very effective, environmentally friendly and can be widely applied for EOR at oilfields

\section{REFERENCES}

[1] Lakatos I., Lakatos-Szabo G., Szentes G.: Revival of Green Conformance and IOR/ EOR Technologies: Nanosilica Aided Silicate Systems - A Review. SPE International Conference and Exhibition on Formation Damage Control, Lafayette, Louisiana, USA, 7-9 February 2018. 
[2] Mo I.K.: An Experimental Study of the Use of Silica and CNC Nanofluids for EOR by Spontaneous Imbibition. Norwegian University of Science and Technology, 2017, 174 p.

[3] Najafiazar B., Yang J., Simon C.R., Karimov F., Torsæter O., Holt T.: Transport Properties of Functionalised Silica Nanoparticles in Porous Media. SPE Bergen One Day Seminar, Bergen, Norway, 20 April 2016, pp. 1-15.

[4] Tarafdar J., Adhikari T.: Nanotechnology in Soil Science. In: Soil Science: An Introduction., Chapter: Nanotechnology in Soil Science, 2015, pp. 775-807

[5] Tarek M.: Investigating Nano-fluid Mixture Effects to Enhance Oil Recovery. SPE Annual Technical Conference and Exhibition, Houston, Texas, USA, 28-30 September 2015.

[6] Li S., Hendraningrat L., Torsćter O.: Improved Oil Recovery by Hydrophilic Silica Nanoparticles Suspension: 2-Phase Flow Experimental Studies. International Petroleum Technology Conference, Beijing, China, 26-28 March 2013.

[7] Perez J.M.: Iron oxide nanoparticles: hidden talent. Nature Nanotechnology, 2, 2007, pp. 535-536.

[8] Hashemi R., Nassar N.N., Pereira-Almao P.: Nanoparticle technology for heavy oil in-situ upgrading and recovery enhancement: opportunities and challenges. Applied Energy, 133, 2014, pp. 374-387.

[9] Rao C.N.R., Biswas K.: Characterization of nanomaterials by physical methods. Annual Review of Analytical Chemistry, 2, 2009, pp. 435-462.

[10] Strambeanu N., Demetrovici L., Dragos D., Lungu M.: Nanoparticles: Definition, Classification and General Physical Properties. In: Nanoparticles' Promises and Risks, Springer International Publishing, 2015, pp. 3-8.

[11] Cao N., Mohammed M.A., Babadagli T.: Wettability Alteration of Heavy-Oil/Bitumen Containing Carbonates Using Solvents, high pH Solutions and Nano/Ionic Liquids. Offshore Technology Conference, Rio de Janeiro, Brazil, 27-29 October 2015.

[12] Kim B.H., Hackett M.J., Park J., Hyeon T.: Synthesis, characterization, and application of ultrasmall nanoparticles. Chemistry of Materials, 26(1), 2013, pp. 59-71.

[13] Franco C.A., Lozano M.M., Acevedo S., Nassar N.N., Cortés F.B. : Effects of resin I on asphaltene adsorption onto nanoparticles: a novel method for obtaining asphaltenes/ resin isotherms. Energy Fuels, 30, 2015, pp. 264-272.

[14] Nwidee L.N.: Nanoparticles for Enhanced Oil Recovery Processes. PhD thesis, Curtin University, 2017, pp. 1-298.

[15] White R.J., Luque R., Budarin V.L., Clark J.H., Macquarrie D.J.: Supported metal nanoparticles on porous materials, methods and applications. Chemical Society Reviews, 38 (2), 2009, pp. 481-494. 
[16] Amanullah M.D., Al-Tahini A.M.: Nanotechnology - its significance in smart fluid development for oil and gas field application. SPE Saudi Arabia Section Technical Symposium, Al-Khobar, Saudi Arabia, 9-11 May 2009.

[17] Metin C.O., Baran J.R., Nguyen Q.P.: Adsorption of surface functionalized silica nanoparticles onto mineral surfaces and decane/water interface. Journal of Nanoparticle Research, 14 (11), 2012, pp. 1246.

[18] Ahmadi M.A., Shadizadeh S.R.: Induced effect of adding nano silica on adsorption of a natural surfactant onto sandstone rock: experimental and theoretical study. Journal Petroleum Science and Engineering, 112, 2013, pp. 239-247.

[19] Hendraningrat L., Torseater O.: Metal oxide-based nanoparticles: revealing their potential to enhance oil recovery in different wettability systems. Applied Nanoscience, 5 (2), 2015, pp. 181-99.

[20] Salem R.A.M., Hannora A.E.A.: Comparative investigation of nanoparticle effects for improved oil recovery-experimental work. Proceedings of the SPE Kuwait Oil and Gas Show and Conference, Mishref, Kuwait, 11-14 October 2015.

[21] Tarek M.: Investigating Nano-fluid Mixture Effects to Enhance Oil Recovery. SPE Annual Technical Conference and Exhibition, Houston, Texas, USA, 28-30 September 2015.

[22] Almohsin A., Bai B., Imqam A., Wei M., Kang W., Delshad M., Sepehrnoori K.: Transport of Nanogel through Porous Media and Its Resistance to Water flow. SPE Improved Oil Recovery Symposium, Tulsa, Oklahoma, USA, 12-16 April 2014.

[23] Dębińska E.: Wpływ nanokrzemionki na parametry mechaniczne kamienia cementowego, Nafta-Gaz, 4, 2014, pp. 229-235.

[24] Chengara A., Nikolov A.D., Wasan D.T., Trokhymchuk A., Henderson D.: Spreading of nanofluids driven by the structural disjoining pressure gradient. Available: www.sciencedirect.com.

[25] Wasan D., Nikolov A., Kondiparty K.: The Wetting and Spreading of Nanofluids on Solids: Role of the Structural Disjoining Pressure. Department of Chemical and Biological Engineering, Illinois Institute of Technology, Chicago, USA, 2011.

[26] Baoliang P., Zhang L., Luo J., Ding P. W. B., Zengc M., Cheng Z.: A review of nanomaterials for nanofluid enhanced oil recovery. RSC Advances, 7, 2017, pp. 32246-32254.

[27] Kamal M.S., Adewunmi A.A., Sultan A.S., Al-Hamad M.F., Mehmood U.: Recent Advances in Nanoparticles Enhanced Oil Recovery: Rheology, Interfacial Tension, Oil Recovery, and Wettability Alteration. Journal of Nanomaterials, 2017, 15 pp.

[28] Aurand K.: Using nanofluids to enhance oil recovery. NTNU TechZone, 3 May 2015. 
[29] Ehtesabi H., Ahadian M.M., Taghikhani W., Ghazanfari M.H.: Enhanced Heavy Oil Recovery in Sandstone Cores Using $\mathrm{TiO}_{2}$ Nanofluids. Energy \& Fuels, www.pubs.acs.org/EF, Teheran, Iran, 2013.

[30] Metin C., Bonnecaze R.T., Nguyen Q.P.: The Viscosity of Silica Nanoparticle Dispersions in Permeable Media. SPE International Oilfield Nanotechnology Conference and Exhibition, The Netherlands, 12-14 June 2012.

[31] Ahmadi M.A., Galedarzadeh M., Shadizadeh S.R.: Wettability alteration in carbonate rocks by implementing new derived natural surfactant: enhanced oil recovery applications. Transport in Porous Media, 106, 3, 2015, pp. 645-667.

[32] Mullins O.C., Sheu E.Y.: Structure and Dynamics of Asphaltenes. Springer, New York 1998.

[33] Al-Anssari S., Nwidee L.N., Ali M., Sangwai S.J., Wang S., Barifcani A., Iglauer S.: Retention of Silica Nanoparticles in Limestone Porous Media. SPE/IATMI Asia Pacific Oil \& Gas Conference and Exhibition, Jakarta, Indonesia, 17-19 October 2017.

[34] Nazari M.R., Bahramian A., Fakhroueian Z., Karimi A., Arya S.: Comparative study of using nanoparticles for enhanced oil recovery: wettability alteration of carbonate rocks. Energy and Fuels, 29, 4, 2015, pp. 2111-2119.

[35] Karimi A., Fakhroueian Z., Bahramian A., Khiabani N.P., Darabad J.B., Azin R., Arya S.: Wettability Alteration in Carbonates using Zirconium Oxide Nanofluids: EOR Implications. Energy Fuels, 26, 2012, pp. 1028-1036.

[36] Sepehrinia K., Mohammadi A.: Wettability Alteration Properties of Fluorinated Silica Nanoparticles in Liquid-Loaded Pores: An Atomistic Simulation. Applied Surface Science, 371, 2016, pp. 349-59.

[37] Tola S., Sasaki K., Sugai Y.: Wettability alteration of sandstone with zinc oxide nano-particles. The 23rd Formation Evaluation Symposium of Japan, 11-12 October 2017.

[38] Bayat A.E., Junin R., Samsuri A., Piroozian A., Hokmabadi M.: Impact of metal oxide nanoparticles on enhanced oil recovery from limestone media at several temperatures. Energy and Fuels, 28, 10, 2014, pp. 6255-6266.

[39] Ju B., Fan T., Ma M.: Enhanced oil recovery by flooding with hydrophilic nanoparticles. China Particuology, 4 (1), 2006, pp. 41-46.

[40] Gu C.-Y., Di Q.-F., Fang H.-P.: Slip Velocity Model of Porous Walls Absorbed by Hydrophobic Nanoparticles $\mathrm{SiO}_{2}$. Journal of Hydrodynamics, 19 (3), 2007, pp. 365-371.

[41] Sun L., Lin J-Z., Bao F-B.: Numerical Simulation on the Deposition of Nanoparticles Under Laminar Conditions. Journal of Hydrodynamics, 18 (6), 2006, pp. 676-680. 
[42] Bazazi P., Gates I.D., Nezhad A.S., Hejazi S.H.: Silica-Based Nanofluid Heavy Oil Recovery A Microfluidic Approach. SPE Canada Heavy Oil Technical Conference, Calgary, Alberta, Canada, 15-16 February 2017.

[43] Kazemzadeh Y., Eshraghi S.E., Kazemi K., Sourani S., Mehrabi M., Ahmadi Y.: Behavior of asphaltene adsorption onto the metal oxide nanoparticle surface and its effect on heavy oil recovery. Industrial and Engineering Chemistry Research, 54, 1, 2015, pp. 233-239.

[44] Alomair O.A., Matar K.M., Alsaeed Y.H.: Nanofluids application for heavy oil recovery. Proceedings of the SPE Asia Pacific Oil and Gas Conference and Exhibition - Changing the Game: Opportunities, Challenges and Solutions, APOGCE 2014, October 2014, pp. 1346-1363.

[45] Roustaei A., Saffarzadeh S., Mohammadi M.: An evaluation of modified silica nanoparticles' efficiency in enhancing oil recovery of light and intermediate oil reservoirs. Egyptian Journal of Petroleum, 22, 3, 2013, pp. 427-433.

[46] Hendraningrat L., Li S., Torsaeter O.: A coreflood investigation of nanofluid enhanced oil recovery. Journal of Petroleum Science and Engineering, 111, 2013, pp. $128-138$.

[47] Ogolo N.A., Olafuyi O.A., Onyekonwu M.O.: Enhanced Oil Recovery Using Nanoparticles. SPE Saudi Arabia section technical symposium and exhibition, Al-Khobar, Saudi Arabia, 2012, p. 9.

[48] Li S., Genys M., Wang K., Trosaeter O.: Experimental study of wettability alteration during nanofluid enhanced oil recovery process and its effect on oil recovery. SPE Reservoir Characterisation and Simulation Conference and Exhibition, Abu Dhabi, UAE, 14-16 September 2015.

[49] Sun X., Zhang Y., Chen G., Gai Z.: Application of Nanoparticles in Enhanced Oil Recovery: A Critical Review of Recent Progress. Energies, 10(3), 2017, p. 345. 